\title{
Molecular edge effects in the Endangered golden-brown mouse lemur Microcebus ravelobensis
}

\author{
U. Radespiel, J. Schulte, R. J. Burke and S. M. Lehman
}

\begin{abstract}
Habitat fragmentation creates habitat edges, and ecological edge effects can cause major changes in the ecology and distribution of many taxa. However, these ecological changes may in turn influence animal movements and lead to molecular edge effects and edge-related genetic structure, matters that are largely unexplored. This study aims to infer molecular edge effects and to test three possible underlying mechanisms in the Endangered golden-brown mouse lemur Microcebus ravelobensis, a nocturnal species in the dry deciduous forest of the Ankarafantsika National Park in north-western Madagascar. Mouse lemurs were sampled in one edge and two interior habitats in close proximity to each other $(500-1,400 \mathrm{~m})$ in a continuous forest. A total of 41 mouse lemur samples were genotyped with seven nuclear microsatellites, and a fragment of the mitochondrial control region was sequenced for all samples. The overall genetic diversity (allelic richness, heterozygosity, haplotype richness, nucleotide diversity) was lower in the edge habitat compared to the two interior sites and all subpopulations showed signals of relatively low genetic exchange and significant genetic differentiation between them despite the short geographical distances, supporting the local preference model. These findings can be interpreted as preliminary signals of a molecular edge effect and suggest the potential for local adaptation. They are highly relevant for the conservation of fragmented populations, because a further subdivision of already small populations may increase their vulnerability to stochastic demographic changes and collapse.
\end{abstract}

Keywords Conservation, dispersal, forest fragmentation, genetic differentiation, genetic diversity, Madagascar, Microcebus ravelobensis, tropical dry forest

\section{Introduction}

Corest fragmentation and loss are occurring at accelerat- ing rates in tropical rainforests. The combined effects of

UTE RADESPIEL (Corresponding author) and JeNNifer SChUlte Institute of Zoology, University of Veterinary Medicine Hannover, Buenteweg 17, 30559 Hannover, Germany. E-mail Ute.radespiel@tiho-hannover.de

Ryan J. Burke* and Shawn M. Lehman Department of Anthropology, University of Toronto, Toronto, Canada

${ }^{*}$ Also at: Department of Zoology, University of Oxford, Oxford, UK

Received 26 July 2017. Revision requested 16 October 2017.

Accepted 11 January 2018. First published online 18 July 2018. these forest conversion processes are among the main drivers of biodiversity loss (Laurance, 1999; Brinck et al., 2017). Forest fragmentation also creates edge effects resulting from the interaction of abiotic and biotic variables between adjacent ecosystems (Murcia, 1995; Ries et al., 2004). Edge effects can cause major changes in the ecology and biogeography of many tropical species (Laurance et al., 2007; Ewers \& Didham, 2008; Crowley et al., 2012).

Understanding how plants and animals respond to forest fragmentation and edge effects is crucial for conservation planning (Ries et al., 2017). Although tropical dry forest is the most threatened ecosystem (Sagar \& Singh, 2006), there are relatively few data on edge effects in tropical dry forests compared to humid, lowland forests (Malcolm et al., 2017). Unlike humid forests, tropical dry forests are largely constrained by the availability of ground water, which affects plant biomass, stem density and species composition (Williams-Linera \& Lorea, 2009). Little is known about how animals respond to edge effects in tropical dry forests (Maffei et al., 2005). Changes in rainfall and ambient air temperature caused by global warming may create further challenges for plant and animal communities in edge habitats in tropical dry forests (Valenta \& Lehman, 2016). Thus, there is an urgent need to examine the impact of forest fragmentation and edge effects on plant and animal communities in these forests.

Studies of forest fragmentation should consider edge effects because fragment area (patch size) relates to edge effects in two ways: firstly, small forest patches tend to have small population sizes and high extinction probabilities (MacArthur \& Wilson, 1967). Secondly, small patches also have a high ratio of fragment perimeter to area, resulting in a higher proportion of edge habitats in these patches (Gascon et al., 2000). This proportion increases with any further reduction in the size of a forest patch, resulting in small forest patches consisting largely of edge habitats with few or no interior or core area habitats. Animals unable to adapt to pervasive and increasing edge effects may be extirpated from small patches (Forman \& Godron, 1981) or may have to increase their movement between isolated patches. The combination of increasing edge effects in forest fragments and animal movements relating to these ecological changes may further increase the overall effects of forest fragmentation beyond forest loss (i.e. area effects), particularly at a landscape scale (Fahrig, 2003).

Interactions between edge effects and animal dispersal patterns are a critical yet largely unexplored aspect of conservation genetics. Several empirical studies have examined 
cross-edge spillover of insect predators and spatial patterns of seed dispersal between active and fallow agricultural fields (Rand et al., 2006; Gorchov et al., 2013). In all of these studies stronger edge effects were reported between natural and anthropogenic habitats; however, a lack of genetic research has led to an inability to extend these studies from basic biogeographical patterns to genetic variation of animals in fragmented landscapes. When residing in patches, animals in established ranges have a low probability of attempting dispersal to other fragments because they have the necessary resources and mating opportunities for survival nearby (Kareiva et al., 1990). Individuals lacking established ranges are more likely to disperse further to acquire resources and mates (i.e. they are nomadic) (Johnson \& Gaines, 1990). The ability to model accurately how edge effects influence dispersal dynamics and genetic variation will benefit our understanding of the diverse processes affecting fragmented ecosystems.

Lemurs are an important group for studying edge effects because they are endemic to Madagascar, which contains some of the rarest and most fragmented forest ecosystems (Schwitzer et al., 2014). Studies of grey mouse lemurs Microcebus murinus and Endangered golden brown mouse lemurs Microcebus ravelobensis indicate both intraand interspecific variations in their distribution, abundance and edge effects in north-western Madagascar (Rendigs et al., 2003; Rakotondravony \& Radespiel, 2009; Burke \& Lehman, 2014). These small (30-70 g) nocturnal lemurs are sympatric throughout much of their range, but they exhibit a negative relationship in abundance in continuous forests (Rakotondravony \& Radespiel, 2009; Burke \& Lehman, 2014) and a positive relationship in abundance in fragmented forests (Steffens \& Lehman, 2016). Microcebus ravelobensis forms mixed-sex sleeping groups and has moderately male-biased dispersal (Radespiel et al., 2003a, 2009). Conversely, M. murinus usually sleeps alone or in female groups of related individuals, and males are generally the dispersing sex (Radespiel et al., 1998, 2001a, 2003b). Mouse lemurs have been found to disperse up to $1 \mathrm{~km}$ (Schliehe-Diecks et al., 2012). Both species of mouse lemur respond differently to edge effects, as demonstrated (Burke \& Lehman, 2014) by different capture rates for both species in interior vs edge habitats in the Ankarafantsika National Park: $82 \%$ of $M$. murinus were captured in interior habitats, whereas $72 \%$ of $M$. ravelobensis were captured in edge habitats. This indicates that $M$. ravelobensis is a suitable model taxon for more detailed studies of edge effects and raises the question as to whether or not this species also exhibits genetic variations between edge and interior habitats.

Here, we use population genetics tools to infer molecular edge effects in $M$. ravelobensis in a single forest in northwestern Madagascar. To our knowledge, no previous study has tested how edge effects influence small-scale genetic variations in an animal species. In particular, we test three alternative scenarios to see which best fits the observed genetic patterns:

(1) Null model: in contrast to interior habitats, animals cannot immigrate from all directions into edge habitats because of the proximity of an inhospitable matrix. These spatial constraints lead to differences in dispersal opportunities and routes between edge and interior habitats. As a consequence, mouse lemur samples from edge habitats should have lower genetic diversity than mouse lemur samples from interior habitats. However, because of regular small-scale dispersal between adjacent forest areas, no genetic differentiation is expected between edge and interior habitats.

(2) Edge preference model: if the edge is the preferred habitat type (e.g. because of more abundant food resources), immigration into edge habitats can be expected to occur more frequently than emigration away from edge habitats. As a consequence of this net influx, genetic diversity should be equal or even higher in edge habitats compared to the interior.

(3) Local preference model: if individuals prefer their natal habitat type over a different habitat type, this should result in rare movements between edge and interior habitats. As a result, some genetic differentiation between both habitat types, low genetic exchange between habitat types and lower genetic diversity in edge than in interior habitats can be expected because of limited dispersal options for animals living in edge habitats.

\section{Methods}

\section{Study site and sampling}

The study was conducted in the $1,040 \mathrm{~km}^{2}$ Ankarafantsika National Park, which contains the largest remaining tract of dry deciduous forest in north-western Madagascar. Three sampling sites were selected, all located within the same forest (Fig. 1). The first site was a linear transect situated close to the edge (Edge), the second site was a transect located $320-600 \mathrm{~m}$ away from the edge $(600 \mathrm{~m})$ and the third site was a partition of Jardin Botanique A (JBA), with a distance of 1,200-1,300 $\mathrm{m}$ from the forest edge. To replicate the linear capture regime along the edge as closely as possible, sampling at the two other sites was also conducted in a transect-like fashion along an approximately north-south axis (Fig. 1). Mean home range sizes of $M$. ravelobensis have been estimated by radiotelemetry at $0.44^{-2.1}$ ha (Ehresmann, 2000; Weidt et al., 2004), depending on sex, season and site. Based on the maximum average value and assuming a circular home range, animals that are found $>164 \mathrm{~m}$ (estimated home range diameter) away from their maternal relatives were assumed to have dispersed. This means that a different transect can be reached only 


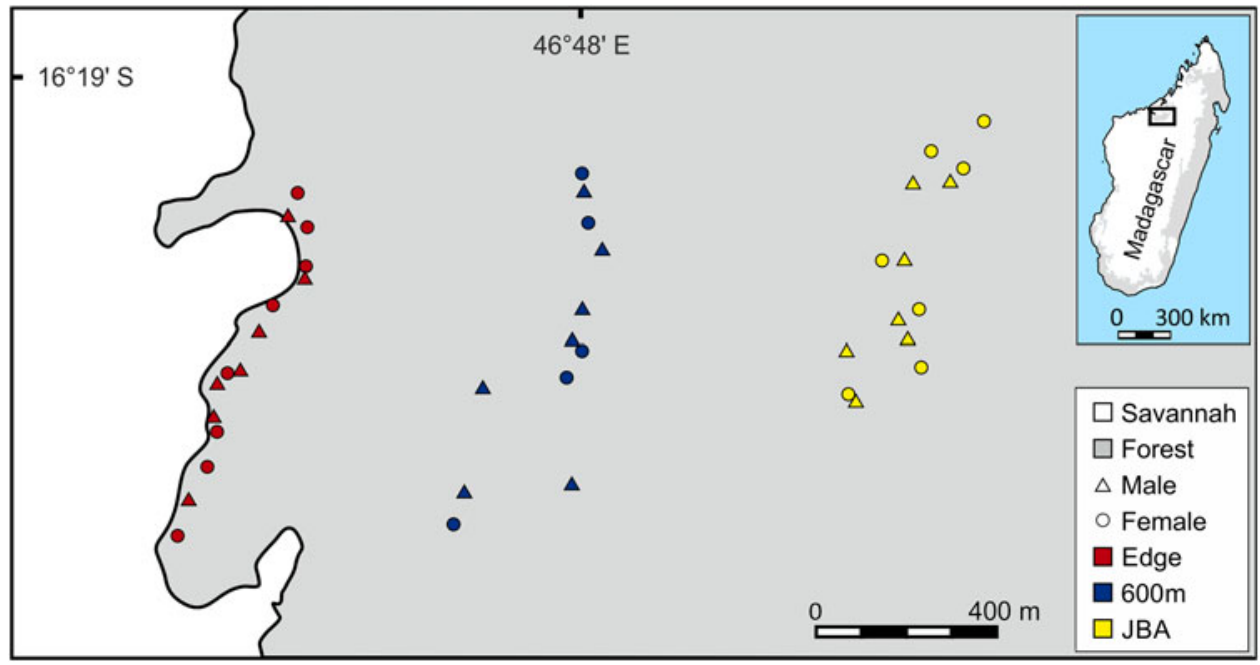

FIG. 1 Map of the study area with the trap locations for Microcebus ravelobensis in three forest sites: Edge (along the forest edge), $600 \mathrm{~m}$ (interior site 320-600 $\mathrm{m}$ away from the forest edge) and JBA (interior site $1,200-1,300 \mathrm{~m}$ away from the forest edge). by dispersal, but not during the daily activities within the natal home range.

The relatively short distance between the sites ensures that inter-site dispersal of individual mouse lemurs is possible (individual golden-brown mouse lemurs have been trapped up to $2 \mathrm{~km}$ from their previous capture site in the Park; UR, E. Zimmermann, SML \& RJB, unpubl. data). Mouse lemurs were trapped with Sherman Live Traps $\left(23.5 \times 8 \times 9 \mathrm{~cm}^{3}\right.$, HB Sherman Traps, Inc., Tallahassee, USA), baited with a piece of banana. Trapping at the Edge site took place 5-50 $\mathrm{m}$ from the forest edge during May-July 2012 (390 trap nights, RJB) and March-May 2014 (260 trap nights, JS) along a transect of c. $800 \mathrm{~m}$ length. Trapping at $600 \mathrm{~m}$ also took place during May-July 2012 (195 trap nights, RJB) and March-May 2014 (260 trap nights, JS) along a transect of c. $800 \mathrm{~m}$ length. Trapping in JBA was conducted in August 2013 (300 trap nights, UR, E. Zimmermann and students) and during March-May 2014 (900 trap nights, JS). Unlike the two transect-based sites Edge and 60om, JBA is accessible via a grid-like network of trails (c. $\left.500 \times 600 \mathrm{~m}^{2}\right)$. For the purpose of this study, a subset of animals trapped within this area was selected that had an approximately linear spatial distribution comparable to that from the other two sites (Fig. 1).

Trapping routines followed those described in Burke \& Lehman (2014) except in March-May 2014. During this time, traps were opened at $16.00-18.00$ and checked at 22.00-0.00 in the same night, to minimize the amount of time that animals spent in the traps, in case lactating females were captured. Females captured during this period were immediately handled, marked, and sampled in the forest and then directly released at their point of capture, whereas males were taken back to the camp for handling and sampling (as during other times). Tissue samples (1-2 $\mathrm{mm}^{2}$ ear biopsies) were taken from all individuals according to established routines (Radespiel et al., 2001a) and stored in
Queen's lysis buffer (Seutin et al., 1991) at ambient temperatures for up to 3 months in Madagascar and then in Germany at $4{ }^{\circ} \mathrm{C}$ until extraction in 2014.

Because $M$. ravelobensis forms kin-based stable sleeping groups (Radespiel et al., 2009) and population genetics methods can be biased by social structure (Parreira \& Chikhi, 2015), we limited the number of close kin in each sample and aimed to include equal numbers of males and females. To achieve this, only one sample from same-sex individuals was included if several were trapped at the same location. Same-sex sampling locations were typically $\geq 50 \mathrm{~m}$ apart (Fig. 1). Following this sampling rule, a total of 41 individuals ( 21 males, 20 females) were available: 15 individuals (7 males, 8 females) from Edge, 12 ( 7 males, 5 females) from 6oom, and 14 (7 males, 7 females) from JBA.

\section{Laboratory procedures}

DNA was extracted with a standard proteinase $\mathrm{K}$ digestion followed by a phenol-chloroform protocol (Sambrook et al., 1989 ) and stored at $-20{ }^{\circ} \mathrm{C}$. PCRs were performed with seven specific microsatellite primers (Table 1) that had been shown to be polymorphic in M. ravelobensis in a previous study (Radespiel et al., 2008). The success of the PCRs was controlled by running aliquots on a $1.5 \%$ agarose gel. The fragment length of the amplified DNA was determined with an ABI 3500 capillary sequencer (Applied Biosystems, Foster City, USA) and raw data were analysed with GeneMapper v. 4.1 (Thermo Fisher Scientific, Waltham, USA) for each microsatellite locus. To minimize genotyping errors, each homozygous sample was re-amplified at least twice. The seven loci were all polymorphic but differed in the number of alleles (range: 7-19), their allelic richness (range: 4.5-12.4) and consequently in their observed $\left(\mathrm{H}_{\mathrm{o}}\right)$ and expected heterozygosity $\left(\mathrm{H}_{\mathrm{e}}\right.$, Table 1$)$. Although $\mathrm{H}_{\mathrm{o}}$ and $\mathrm{H}_{\mathrm{e}}$ differed in some loci (Mm1o, Mm3o, Mm43B), 
TABLE 1 Characteristics of the microsatellite loci used. Sample size for all loci is 41.

\begin{tabular}{llccllll}
\hline Locus & Size range $(\mathrm{bp})^{1}$ & No. alleles & Allelic richness & $\mathrm{H}_{\mathrm{o}}{ }^{2}$ & $\mathrm{H}_{\mathrm{e}}{ }^{3}$ & $\mathrm{HWE}^{4}$ & Reference \\
\hline Mm03 & $105-129$ & 7 & 4.515 & 0.488 & 0.519 & n.s. & Radespiel et al. (2001b) \\
Mm08 & $152-204$ & 19 & 12.431 & 0.927 & 0.917 & n.s. & Radespiel et al. (2001b) \\
Mm09n & $105-126$ & 7 & 5.586 & 0.756 & 0.749 & n.s. & Radespiel et al. (2008) \\
Mm10 & $141-221$ & 16 & 11.752 & 0.756 & 0.924 & $600 \mathrm{~m}$ & Radespiel et al. (2001b) \\
Mm30 & $224-248$ & 10 & 7.172 & 0.610 & 0.794 & Edge & Hapke et al. (2003) \\
Mm40 & $136-158$ & 11 & 7.905 & 0.805 & 0.821 & n.s. & Hapke et al. (2003) \\
Mm43b & $147-167$ & 9 & 7.717 & 0.781 & 0.857 & n.s. & Hapke et al. (2003) \\
\hline
\end{tabular}

${ }^{1}$ Size range of alleles (base pairs).

${ }^{2}$ Observed heterozygosity.

${ }^{3}$ Expected heterozygosity.

${ }^{4}$ Test for Hardy-Weinberg equilibrium (sites with significant deviations are shown).

none of them deviated significantly from Hardy-Weinberg equilibrium in all three sites, and therefore all of them were kept in the subsequent analyses.

In addition to the microsatellite loci, a $529 \mathrm{bp}$ fragment of the mitochondrial control region was amplified via PCR, using the mammalian control region primers L15997 and H16498 (Gerloff et al., 1999). Both strands were sequenced with an ABI 3500 capillary sequencer. The raw sequence data of the two strands of each individual were assembled with SeqMan v. 7.o (DNASTAR, Inc., Madison, USA) and then aligned with all other sequences in MEGA 5.0 (Tamura et al., 2011). An internal region (354 bp), for which all but one of the samples could be sequenced clearly, was chosen and all aligned sequences were cut to that length.

\section{Spatial analyses}

To calculate inter-individual distances, a central trapping point was calculated for each individual by using the geographical coordinates (latitude and longitude in decimal degrees) of each capture location. If an individual was caught at more than one location, the coordinates of its central trapping point were calculated as a weighted average of all trapping points. Weighing was according to capture frequency; i.e. the coordinates of a site with a double capture were counted twice, whereas each singular capture event was counted only once. Using the coordinates of the individual central home points, inter-individual distances were calculated with the formula:

$$
\begin{aligned}
& d=\left(1 . 6 0 9 3 4 4 ^ { * } \left(3963^{*} \arccos (\cos (\operatorname{radian}(90-\text { lat } 1))\right.\right. \\
& *(\cos (\operatorname{radian}(90-\text { lat } 2))+(\sin (\operatorname{radian}(90-\text { lat } 1)) \\
& *(\sin (\operatorname{radian}(90-\text { lat } 2)) *(\cos (\operatorname{radian}(\text { lon } 1-\text { lon } 2))))))^{*} 1000
\end{aligned}
$$

where $\mathrm{d}=$ distance $(\mathrm{m})$, lat $=$ latitude, lon $=$ longitude, lat $/$ lon $1=$ of first individual, lat/lon $2=$ of second individual. Intra-site distances $($ mean $=261.8 \pm$ SD $158.7 \mathrm{~m})$ were significantly shorter than inter-site distances (mean $=1003.1 \pm \mathrm{SD}_{362.5} \mathrm{~m}$, Mann-Whitney U Test, $Z=-22.73, \mathrm{n} 1=262, \mathrm{n} 2=558$,
$\mathrm{P}<0.00001$ ), but because of the relative proximity of the sites, $15.7 \%$ (41 of 262) distances within sites were longer than the minimum distance $(435 \mathrm{~m})$ between sites.

\section{Molecular analyses}

\section{Genetic diversity}

Hardy-Weinberg equilibrium was tested for all loci and sites separately with Genetix 4.05 (Belkhir et al., 1996) with 10,000 permutations. Genetix 4.05 and FSTAT 2.9.2.3 (Goudet, 1995) were used to calculate the observed heterozygosity $\left(\mathrm{H}_{\mathrm{o}}\right)$, expected heterozygosity $\left(\mathrm{H}_{\mathrm{e}}\right)$ and inbreeding coefficient $\left(F_{\mathrm{is}}\right)$ for each locus across all sites and for each site and all loci separately. The standardized allelic richness was calculated with FSTAT 2.9.2.3 for each locus and these were averaged per site. All measures of genetic diversity were compared between sites by means of a non-parametric Wilcoxon signed-rank test with Statistica 6.o (StatSoft Inc., Tulsa, USA) with one data point per locus and site. The number of mitochondrial haplotypes, haplotype diversity and nucleotide diversity were calculated with DnaSP 5.10.01 (Librado \& Rozas, 2009) for each site.

\section{Genetic exchange between sites}

We performed spatial autocorrelation analyses, then applied an assignment test to the genotype dataset and finally analysed the sequence dataset in more detail using a haplotype network. The spatial autocorrelation was performed with SPAGeDi 1.4 (Hardy \& Vekemans, 2002) to analyse how genetic relationships are related to geographical distance and whether there are indications for genetic structure in the dataset. This analysis was based on all multilocus genotypes and related inter-individual genetic relationships (Moran's I values; Hardy \& Vekemans, 1999) to the geographical distance between individuals across five distance classes (100, 200, 500, 1,0000 and 2,000 m). The significance of the Moran's I values within each distance class was tested with 10,000 permutations of individual locations among all 
individuals. The observed mean Moran's I value is displayed together with the $5 \%$ and $95 \%$ confidence interval determined by permutation for each distance class to visualize significantly positive or negative deviations of the Moran's I, respectively. Because of the spatial setting of the study, the first two distance classes (100 and $200 \mathrm{~m}$ ) contained only pairs of lemurs from the same transect, and only few $(n=5,3.6 \%)$ values in the $500 \mathrm{~m}$ class resulted from intertransect comparisons. In contrast, almost all values from the $1 \mathrm{~km}$ distance class $(\mathrm{n}=315,92.4 \%)$ and all values from the 2 $\mathrm{km}$ distance class resulted from inter-transect comparisons. Therefore, the comparison between distance classes also facilitates the comparison of Moran's I within and between transects. To detect any potential sex bias in dispersal, the analysis was also performed for both sexes separately.

The Bayesian assignment method of Rannala \& Mountain (1997) was used to assign individuals to their most likely site of origin (Edge, 6oom or JBA) using GeneClass2 v2.o (Piry et al., 2004). The assignment probabilities were calculated according to Paetkau et al. (2004). If gene flow between the sites is restricted and the allele distributions differ as a consequence of genetic drift or non-random mating, animals can be assigned to their geographical origin with some degree of certainty. To infer recent migration rates, a Markov chain Monte Carlo analysis was performed with BayesAss 3.0.4 (Wilson \& Rannala, 2003). The programme was run four times with 10 million iterations each, discarding the first 1 million iterations as burn-in and sampling every 1ooth of the remaining 9 million iterations to estimate parameters. Acceptance rates for changes in allele frequencies and in the inbreeding coefficient were adjusted to below $60 \%$ (as recommended in the manual) by changing the respective mixing parameters, i.e. by setting the proposed move step sizes to $a=0.5$ (for changes to the allele frequency) and to $f=0.7$ (for changes to the inbreeding coefficient). The trace files of the runs were checked for convergence with Tracer (Rambaut et al., 2014). The programme provides inferred (posterior mean) migration rates and the standard deviation of their marginal posterior distribution. The resulting migration rates and standard deviations were averaged across all four runs.

We inferred maternal genetic exchange from the analysis of the mitochondrial haplotypes and from the haplotype network drawn with Network 4.6.1.o (Bandelt et al., 1999) by means of the median joining method. Finally, we identified potential male immigrants by a haplotype that was not shared with females from that site. In contrast, males that shared a haplotype with females in a given site were categorized as potentially philopatric males. Given these categories, the percentage of potential migrants and the proportion of immigrant to philopatric males were calculated for each site. We acknowledge that this approach does not identify the exact geographical origin of all males and that the real dispersal rates cannot be accurately determined. However, because the analysis was performed in the same way for all three sites, the results nevertheless allow a site comparison with regard to relative differences in dispersal tendencies. To estimate the genetic differentiation among the three sites, pairwise fixation indices $\left(F_{\mathrm{st}}\right.$; Weir \& Cockerham, 1984) were calculated and tested for significance using 10,000 permutations with Genetix 4.05.

\section{Results}

\section{Genetic diversity in the edge vs forest interior}

Among all three sites, JBA had the highest genetic diversity, which was expressed in the highest overall allelic richness, high values of $\mathrm{H}_{\mathrm{o}}$ and $\mathrm{H}_{\mathrm{e}}$, and the highest number of haplotypes, haplotype diversity and nucleotide diversity (Table 2). The samples from $600 \mathrm{~m}$ showed an intermediate diversity, as they had comparable values of $\mathrm{H}_{\mathrm{o}}$ and $\mathrm{H}_{\mathrm{e}}$ to JBA, but an intermediate value of allelic richness and low values of haplotype diversity and nucleotide diversity. The samples from the Edge were characterized by the lowest values of allelic richness, $\mathrm{H}_{\mathrm{o}}, \mathrm{H}_{\mathrm{e}}$, and nucleotide diversity, but a relatively high haplotype diversity. Although the allelic richness at the Edge was smaller than that of $600 \mathrm{~m}$ and JBA in five of seven loci and in six of seven loci, respectively, this difference was not significant (Wilcoxon Test, $Z<1.521$, $\mathrm{n}=7$, n.s.). Similarly, there was no significant difference between the $\mathrm{H}_{\mathrm{o}}$ or $\mathrm{F}_{\text {is }}$ values of the Edge and 6oom or JBA, respectively (Wilcoxon Test, $\mathrm{Z}<1.183, \mathrm{n}=7$, n.s.). However, the Edge had a significantly lower expected heterozygosity than 6oom (Wilcoxon Test, $Z=2.366, \mathrm{n}=7, \mathrm{P}<0.05$ ) but not lower than JBA (Wilcoxon Test, $Z=1.521, \mathrm{n}=7$, n.s.).

\section{Genetic exchange vs differentiation between the edge and forest interior}

The spatial autocorrelation analysis revealed that Moran's I values were significantly higher than expected only within sites and within the two lowest distance classes $(\leq 200 \mathrm{~m}$ for both sexes, Fig. 2) and significantly lower than expected within the $1000 \mathrm{~m}$ distance class (females) or above 1,000 $\mathrm{m}$ (males and both sexes, Fig. 2). Female average values ranged above male values only in the first distance class $(\leq 100 \mathrm{~m})$. Overall, the mean Moran's I fell below zero (random relatedness) beyond $200 \mathrm{~m}$ (both sexes and males) or beyond $500 \mathrm{~m}$ (females, Fig. 2b,c), i.e. still within each site.

All but four individuals were correctly assigned to their capture sites by the assignment test. These four individuals were all males, three of which were trapped at the Edge and one at $600 \mathrm{~m}$. These males carried mitochondrial haplotypes that were either shared between sites $(n=3)$ or unique and shared with no other individual $(n=1)$. Pairwise genetic differentiation was calculated between the sites based on the 
TABLE 2 Genetic diversity measures of the three study sites. The test for Hardy-Weinberg equilibrium was not significant in all cases.

\begin{tabular}{lllllllll}
\hline Site & $\begin{array}{l}\text { Sample size } \\
(\mathrm{m}, \mathrm{f})\end{array}$ & $\begin{array}{l}\text { Allelic } \\
\text { richness }\end{array}$ & $\mathrm{H}_{\mathrm{o}}{ }^{1}$ & $\mathrm{H}_{\mathrm{e}}{ }^{2}$ & $F_{\mathrm{is}}{ }^{3}$ & $\begin{array}{l}\text { No. of mitochondrial } \\
\text { haplotypes }\end{array}$ & $\begin{array}{l}\text { Haplotype } \\
\text { diversity }\end{array}$ & $\begin{array}{l}\text { Nucleotide } \\
\text { diversity }\end{array}$ \\
\hline Edge & $15(7,8)$ & 7.565 & 0.695 & 0.733 & 0.053 & 5 & 0.752 & 0.021 \\
600m & $12(7,5)$ & 7.857 & 0.750 & 0.812 & 0.079 & 4 & 0.673 & 0.024 \\
JBA & $14(7,7)$ & 8.264 & 0.755 & 0.806 & 0.065 & 7 & 0.758 & 0.036 \\
\hline
\end{tabular}

${ }^{1}$ Observed heterozygosity.

${ }^{2}$ Expected heterozygosity.

${ }^{3}$ Inbreeding coefficient.

multilocus genotypes and was significant in all three cases $\left(\mathrm{F}_{\text {stEdge-60om }}=0.0218, \quad \mathrm{P}<0.05, \quad \mathrm{~F}_{\text {stEdge }-\mathrm{JBA}}=0.0331\right.$, $\left.\mathrm{P}<0.01, \mathrm{~F}_{\text {st6oom-JBA }}=0.0293, \mathrm{P}<0.05\right)$, with the highest value between the Edge and JBA. The fraction of immigrating individuals (determined with BayesAss) differed between sites. Whereas $88.5 \pm 6.7 \%$ of the Edge sample were inferred as stemming from the Edge (no migration background), this proportion was only $75.2 \pm 5.6 \%$ for $600 \mathrm{~m}$ and $72.2 \pm 5.1 \%$ for JBA. This suggests that the immigration rate was higher in the two core sites (c. 25 and $28 \%$, respectively) than in Edge (c. 12\%).

A total of 12 different mitochondrial haplotypes were identified (Table 3). Three of these $\left(\mathrm{H}_{1}, \mathrm{H}_{2}, \mathrm{H}_{3}\right)$ were shared between sites, but all others were private haplotypes of one site only. If haplotypes were shared, they were typically shared by males and females of the sites (exception: one male in JBA sharing $\mathrm{H}_{2}$ with Edge and 6oom).

Congruent to this pattern of haplotype sharing, the haplotypes were not clustered by site in the haplotype network but were mixed, with one haplotype (H11) differing from the others by more than 20 mutation steps (Fig. 3). Seven of nine unique haplotypes were represented by males and only two by females (Table 3). These potential immigrant males were not evenly distributed between sites. The proportion of potential immigrant males among all samples of the sites was $6.7 \%$ for Edge, $18.2 \%$ for $600 \mathrm{~m}$, and $28.6 \%$ for JBA. The proportion of potential immigrants among all males was $13.4 \%$ for Edge, $28.6 \%$ for $600 \mathrm{~m}$, and $57.1 \%$ for JBA. Consequently, the proportion of potential immigrants to philopatric males was 1:6 for Edge, 2:5 for $600 \mathrm{~m}$, and 4:3 for JBA.

\section{Discussion}

This study aimed to investigate signals of possible genetic edge effects in the Endangered golden-brown mouse lemur and found preliminary evidence for them. The overall summary statistics of the genetic diversity measures (allelic richness, observed and expected heterozygosity, number of haplotypes, haplotype and nucleotide richness) have generally lower values in the edge habitat compared to both interior habitats, supporting the prediction of the null model and the local preference model. However, the marker-specific statistical comparisons between sites were significantly different only in the case of expected heterozygosity, although these tests may have been constrained in power by the limited number of microsatellite markers $(n=7)$ that were available for this study.

The study revealed signals of limited genetic exchange between edge and interior habitats and of genetic differentiation between sites. This was evident in (1) negative values of Moran's I in the higher distance classes that represent the relationships to individuals captured in other sites, (2) high assignment rates of individuals to the site of capture (37 of 41 animals, 90.2\%), despite the local scale of the analyses, (3) only three out of 12 haplotypes (25\%) being shared between sites, and (4) significant $F_{\mathrm{ST}}$ values despite the close proximity of the sites. The significant $F_{\mathrm{ST}}$ values were unexpected because of the short geographical distance between individuals from different sites $(435-1865 \mathrm{~m})$. A previous study on golden-brown mouse lemurs employed eight microsatellite loci and spanned much longer distances of 4-99 km between a set of 12 sub-populations from the Ankarafantsika National Park (Radespiel et al., 2008). $F_{\text {ST }}$ values from that study were $-0.002-0.112$ with 15 of 66 values (22.7\%) being lower than those calculated in this study. Those 15 lower values stemmed from sites that were $5-81 \mathrm{~km}$ apart (Radespiel et al., 2008). A study on the grey mouse lemur in the continuous Kirindy forest (western Madagascar) also revealed a fine-scale genetic structure, but the $F_{\mathrm{ST}}$ values, despite being also significant, were all lower than those calculated here, although the sites were $\geq 1 \mathrm{~km}$ apart (Fredsted et al., 2005). This indicates that the genetic differentiation between edge and interior observed in this study is substantial.

However, the lack of connectivity between the edge and interior of the forest cannot be explained with a general lack of migratory movements. Each site contained individuals with private haplotypes (potential immigrants), but they were not evenly distributed between sites and sexes. Very few potential immigrants could be identified in the Edge $(n=2)$ and in $600 \mathrm{~m}(\mathrm{n}=2)$, but most of them were found in the interior site JBA $(\mathrm{n}=5)$, and seven of nine potential immigrants were males. The high number of potential male immigrants in JBA is not surprising because males from 


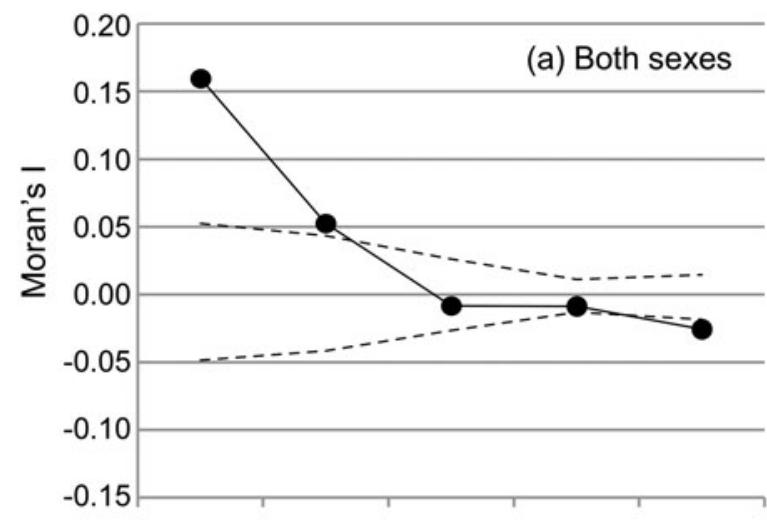

TABLE 3 Number of haplotypes in each sampling site (in parentheses: number of haplotypes in males and females, respectively).

\begin{tabular}{llll}
\hline Haplotype ID & Edge & $600 \mathrm{~m}$ & JBA \\
\hline 1 & $5(2,3)^{1}$ & $3(2,1)^{1}$ & \\
2 & $2(1,1)^{1}$ & $6(3,3)^{1}$ & $1(1,0)^{2}$ \\
3 & $6(3,3)^{1}$ & & $7(2,5)^{1}$ \\
4 & $1(0,1)$ & & $2(1,1)$ \\
5 & & & $1(0,1)$ \\
6 & & & $1(1,0)^{2}$ \\
7 & & & $1(1,0)^{2}$ \\
8 & $1(1,0)^{2}$ & & \\
9 & & $1(1,0)^{2}$ & \\
10 & & & $1(1,0)^{2}$ \\
11 & & 4 & 7 \\
12 & 5 & 11 & 14 \\
No. of haplotypes & 15 & & \\
Sample size & & & \\
\hline
\end{tabular}

${ }^{1}$ Haplotypes shared between sites and also found in females. ${ }^{2}$ Haplotypes exclusively found in males in a given site.

Edge (c. 12\%) by means of Bayesian statistics. These numbers are similar to those derived from the haplotype distribution pattern. Males from the Edge seem to be less likely immigrants (13.5\%) compared to males from the two interior sites $(28.6 \%$ in $600 \mathrm{~m}, 57.1 \%$ in JBA). Most of the Edge males (85.7\%) shared haplotypes with 1-3 females, which may indicate that these males have a higher philopatric tendency and may stay close to their maternal lineage in their native habitat type. These findings also support previous indications of a male-biased dispersal system in this species (Radespiel et al., 2009) and suggest that individuals (particularly males) do move, but are less likely to move between the edge and the interior. However, the total sample size in this study was limited, and rare haplotypes could easily have been missed. Future studies on molecular edge effects should therefore aim to include more animals and more markers to test for genetic isolation between edge and core habitats.

Taken together, these findings are in congruence with the local preference model and indicate that mouse lemurs do not move freely between sites and habitat types. This is unexpected because the three sites are connected by continuous forest and geographical distances between sites are short (500-1,400 $\mathrm{m}$ ) and within the range of dispersal distances known for this and other mouse lemur species (Radespiel et al., 2003b; Schliehe-Diecks et al., 2012; authors unpubl. data). To our knowledge, this is the first preliminary evidence for a small-scale molecular edge effect in forestdwelling animals.

Given the many biotic and abiotic differences that exist other interior locations can enter this site from all directions, whereas migratory options in both other sites are constrained by the proximity to the forest edge or the 'edge zone', respectively. These results were supported by the relatively high immigration rate that was inferred for JBA (c. $28 \%$ ) and $600 \mathrm{~m}$ (c. $25 \%$ ) compared to that inferred for the between the edge zones and the interior of forest habitats (Lehman, 2016), it is not surprising to see the movements of animals being constrained and influenced by these differences. In the case of the golden-brown mouse lemur, it is 


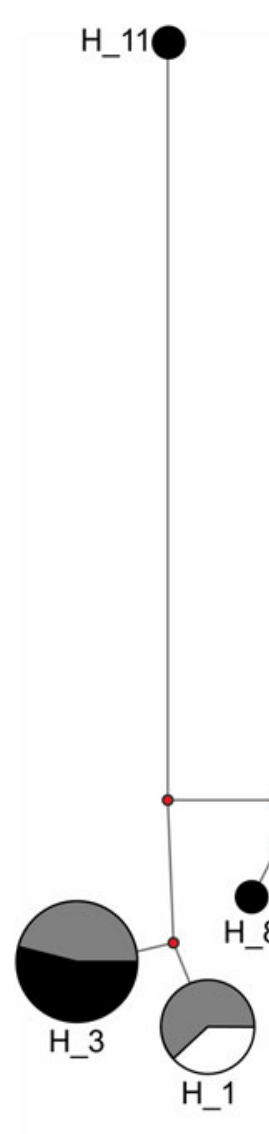

plausible that the different abiotic conditions in both forest parts may translate into differences in resource distribution (e.g. shelter, food and potential mates) or in different threat levels from predators. Under these circumstances, it is likely that the offspring of parents who reproduce successfully in the edge or the interior, respectively, may benefit from staying in their familiar zone. This phenomenon is known as habitat imprinting (Hildén, 1965) and has been used to explain dispersal patterns in fish (Arvedlund \& Nielsen, 1996) and birds (Teuschl et al., 1998). Familiarity with the surroundings is generally believed to be a selective benefit of philopatry (Clobert et al., 2001), and this may also explain a resistance to move between different habitat types (Stamps, 2001). Whether the resistance of mouse lemurs to leave a familiar habitat type may also correspond to molecular adaptive changes leading to heritable local adaptation (Williams, 1966; Savolainen et al., 2013), cannot be answered in this study but merits further scientific attention.

We provide only preliminary evidence for a molecular edge effect because the sample size and the number of the molecular markers employed for this study were limited. Some recent modelling approaches have revealed that signals of genetic structure may be falsely inferred under a biased sampling scheme or if social structure and relatedness between individuals act as confounding factors
(Schwartz \& McKelvey, 2009; Chikhi et al., 2010; Parreira \& Chikhi, 2015). With our spatial setting, however, we have avoided collecting samples that would over-represent clusters of related individuals. The spatial design of our study was chosen to maximize the spatial spread of samples within each site, such that individuals from the opposite ends of each site were as far from each other as individuals from neighbouring sites. We therefore believe that the potentially confounding effects (biased sampling and relatedness) cannot explain our finding of a molecular edge effect and low genetic exchange between sites.

This study has important implications for the effective conservation of threatened species in a largely fragmented landscape. If animals living in an edge habitat do not typically interbreed with individuals inhabiting the interior of the forest, an already fragmented population may be subject to further subdivision. This can lead to a decrease in effective population size, increased inbreeding within each zone (edge or interior), and may in turn increase the vulnerability of each subpopulation to stochastic demographic changes and bottlenecks (Holmes et al., 2013; Frankham et al., 2014). Future studies need to investigate to what extent this edge-interior subdivision of fragmented populations may contribute to the detrimental effects of forest fragmentation that have been described in other model systems. 
Acknowledgements We thank the Ministère de l'Environnement, de l'Ecologie et des Forêts and Madagascar National Parks for granting research permits. UR and JS are grateful to Romule Rakotondravony, Blanchard Randrianambinina, and Solofonirina Rasoloharijaona for their continuous support in Madagascar. UR and JS thank Elke Zimmermann, May Hokan, Sharon Kessler and the field course students Nary Andrianjaka, Imelda B. Fanjasoa, Jasper Götting, Sabrina Just and Jean A. Rakotomanantena for collaborating in trapping mouse lemurs in JBA in 2013, and Sandra Paule Ratsimbazafy for her assistance with fieldwork in 2014. For their support, advice and hospitality, SML and RB thank Benjamin Andriamahaja and the staff at ICTE/MICET, Fanja Raoelinirina, and the staff at La Maison du Pyla. SML and RB thank all those who have assisted us with their research in Madagascar, particularly Blanchard Randrianambinina, Tantely Rakotondriamanga, Jhonny, Radoniaina Rafaliarison, Mamy Razafitsalama, Jean de-la-Dieu and Paul Tsiveraza. We thank Sharon Kessler, Travis Steffens and Kim Valenta for their invaluable input on research design and field methods. UR and JS thank Claudia Ravens and Sabine Sippel for technical assistance and Sönke von den Berg and Tjard Bergmann for technical support. The comments of two anonymous reviewers improved the article. This work was supported financially by a Discovery grant to SML, a CGS-M to RB from the Natural Sciences and Engineering Research Council of Canada and by the Institute of Zoology, Tieräztliche Hochschule Hannover, to JS.

Author contributions Conception of the study, planning of fieldwork and writing of the manuscript: UR and SML; contribution to field work: JS and RJB; molecular work: JS; contribution to data analyses: UR and JS. Revision of final version: all authors.

\section{Conflicts of interest None.}

Ethical standards All field procedures were approved by the Ministère de l'Environnement, de l'Ecologie et des Forêts and Madagascar National Parks (MNP) and necessary research permits were obtained from the respective Malagasy authorities (license $\mathrm{N}^{\circ}$ 111/12/MEF/SG/DFG/DCB SAP/SCB obtained on 16 April 2012, N - $167 / 13 / \mathrm{MEF} / \mathrm{SG} / \mathrm{DGF} / \mathrm{DCB} . S A P / S C B$ obtained on 16 July 2013, and licence $\mathrm{N}^{\circ} 060 / 14 / \mathrm{MEF} / \mathrm{SG} / \mathrm{DGF} / \mathrm{DCB} / \mathrm{SAP} / \mathrm{SCB}$ obtained on 21 February 2014). Research by SML and RB was authorized by the University of Toronto, Office of Research Ethics (protocol No. 20009283). Trapping procedures and sample collection complied with the regulations of the government of Madagascar. The study adhered to the Code of Best Practices for Field Primatology of the International Primatological Society and the ethical guidelines of the Association for the Study of Animal Behaviour and the Animal Behaviour Society.

\section{References}

Arvedlund, M. \& Nielsen, L.E. (1996) Do the anemonefish Amphiprion ocellaris (Pisces: Pomacentridae) imprint themselves to their host sea anemone Heteractis magnifica (Anthozoa: Actinidae)? Ethology, 102, 197-211.

Bandelt, H.J., Forster, P. \& Röhl, A. (1999) Median-joining networks for inferring intraspecific phylogenies. Molecular Biology and Evolution, 16, 37-48.

Belkhir, K., Borsa, P., Chikhi, L., Raufaste, N. \& Bonhomme, F. (1996) GENETIX 4.05, Logiciel Sous Windows TM Pour la Génétique des Populations. Laboratoire Génome, Populations, Interactions, Montpellier, France and CNRS UMR 500o, Université de Montpellier II, Montpellier, France.
Brinck, K., Fischer, R., Groeneveld, J., Lehmann, S., De Paula, M.D., PUTZ, S. et al. (2017) High resolution analysis of tropical forest fragmentation and its impact on the global carbon cycle. Nature Communications, 8, 14855.

BuRKe, R.J. \& LeHMAN, S.M. (2014) Edge effects on morphometrics and body mass in two sympatric species of mouse lemurs in Madagascar. Folia Primatologica, 85, 277-291.

Chikhi, L., Sousa, V.C., Luisi, P., Goossens, B. \& Beaumont, M.A. (2010) The confounding effects of population structure, genetic diversity and the sampling scheme on the detection and quantification of population size changes. Genetics, 186, 983-995.

Clobert, J., Danchin, E., Dhondt, A.A. \& Nichols, J.D. (2001) Dispersal. Oxford University Press, New York, USA.

Crowley, B.E., McGoogan, K.C. \& Lehman, S.M. (2012) Edge effects on foliar stable isotope values in a Madagascan tropical dry forest. PLOS ONE, 7, e44538.

Ehresmann, P. (2000) Ökologische Differenzierung von zwei sympatrischen Mausmaki-Arten (Microcebus murinus und M. ravelobensis) im Trockenwald Nordwest-Madagaskars. $\mathrm{PhD}$ thesis, University of Hannover, Germany.

Ewers, R.M. \& Didham, R.K. (2008) Pervasive impact of large-scale edge effects on a beetle community. Proceedings of the National Academy of Sciences of the United States of America, 105, 5426-5429.

FAHRIG, L. (2003) Effects of habitat fragmentation on biodiversity. Annual Review of Ecology, Evolution and Systematics, 34, 487-515.

Forman, R.T. \& Godron, M. (1981) Patches and structural components for a landscape ecology. BioScience, 31, 733-740.

Frankham, R., Bradshaw, C.J.A. \& Brook, B.W. (2014) Genetics in conservation management: revised recommendations for the 50/500 rules, Red List criteria and population viability analyses. Biological Conservation, 170, 56-63.

Fredsted, T., Pertoldi, C., Schierup, M.H. \& Kappeler, P.M. (2005) Microsatellite analyses reveal fine-scale genetic structure in grey mouse lemurs (Microcebus murinus). Molecular Ecology, 14, 2363-2372.

Gascon, C., Williamson, G.B. \& da Fonseca, G.A.B. (2000) Receding forest edges and vanishing reserves. Science, 288, 13561358.

Gerloff, U., Hartung, B., Fruth, B., Hohmann, G. \& Tautz, D. (1999) Intracommunity relationships, dispersal pattern and paternity success in a wild living community of bonobos (Pan paniscus) determined from DNA analysis of faecal samples. Proceedings of the Royal Society of London Series B-Biological Science, 266, 1189-1195.

Gorchov, D.L., Rondon, X.J., Cornejo, F., Schaefer, R.L., JANosko, J.M. \& SLutZ, G. (2013) Edge effects in recruitment of trees, and relationship to seed dispersal patterns, in cleared strips in the Peruvian Amazon. Ecological Research, 28, 53-65.

GoudET, J. (1995) FSTAT (version 1.2): a computer program to calculate F-statistics. Journal of Heredity, 86, 485-486.

Hapke, A., Eberle, M. \& Zischler, H. (2003) Isolation of new microsatellite markers and application in four species of mouse lemurs (Microcebus sp.). Molecular Ecology Notes, 3, 205-208.

Hardy, O.J. \& Vekemans, X. (1999) Isolation by distance in a continuous population: reconciliation between spatial autocorrelation analysis and population genetics models. Heredity, 83, 145-154.

Hardy, O.J. \& Vekemans, X. (2002) SPAGedi: a versatile computer program to analyse spatial genetic structure at the individual or population levels. Molecular Ecology Notes, 2, 618-620.

Hildén, O. (1965) Habitat selection in birds: A review. Annales Zoologici Fennici, 2, 53-75.

Holmes, S.M., Baden, A.L., Brenneman, R.A., Engberg, S.E., Louis, E.E. \& Johnson, S.E. (2013) Patch size and isolation 
influence genetic patterns in black-and-white ruffed lemur (Varecia variegata) populations. Conservation Genetics, 14, 615-624.

Johnson, M.L. \& Gaines, M.S. (1990) Evolution of dispersal: theoretical models and empirical tests using birds and mammals. Annual Review of Ecology and Systematics, 21, 449-480.

Kareiva, P., Mullen, A. \& Southwood, R (1990) Population dynamics in spatially complex environments: theory and data (and discussion). Philosophical Transactions of the Royal Society London B: Biological Sciences, 330, 175-190.

Laurance, W.F. (1999) Reflections on the tropical deforestation crisis. Biological Conservation, 91, 109-117.

Laurance, W.F., Nascimento, H.E.M., Laurance, S.G., Andrade, A., Ewers, R.M., Harms, K.E. et al. (2007) Habitat fragmentation, variable edge effects, and the landscape-divergence hypothesis. PLoS ONE, 2, e1017.

LEHMAN, S.M. (2016) Edge effects on tree dendrometrics, abiotics, and mouse lemur densities in western dry forests in Madagascar. In The Dwarf and Mouse Lemurs of Madagascar (eds S.M. Lehman, U. Radespiel \& E. Zimmermann), pp. 464-478. Cambridge University Press, Cambridge, UK.

Librado, P. \& Rozas, J. (2009) DnaSP v5: a software for comprehensive analysis of DNA polymorphism data. Bioinformatics, 25, 1451-1452.

MacArthur, R.H. \& Wilson, E.O. (1967) The Theory of Island Biogeography. Princeton University Press, Princeton, USA.

Maffei, L., Noss, A.J., Cuéllar, E. \& Rumiz, D.I. (2005) Ocelot (Felis pardalis) population densities, activity, and ranging behaviour in the dry forests of eastern Bolivia: data from camera trapping. Journal of Tropical Ecology, 21, 349-353.

Malcolm, J.R., Valenta, K.A. \& Lehman, S.M. (2017) Edge effects in tropical dry forests of Madagascar: additivity or synergy? Landscape Ecology, 32, 327-341.

Murcia, C. (1995) Edge effects in fragmented forests: implications for conservation. Trends in Ecology and Evolution, 10, 58-62.

Paetkau, D., Slade, R., Burden, M. \& Estoup, A. (2004) Genetic assignment methods for the direct, real-time estimation of migration rate: a simulation-based exploration of accuracy and power. Molecular Ecology, 13, 55-65.

PARREIRA, B.R. \& CHIKHI, L. (2015) On some genetic consequences of social structure, mating systems, dispersal, and sampling. Proceedings of the National Academy of Sciences of the United States

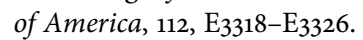

Piry, S., Alapetite, A., Cornuet, J.M., Paetkau, D., Baudouin, L. \& Estoup, A. (2004) GENECLASS2: a software for genetic assignment and first-generation migrant detection. Journal of Heredity, 95, 536-539.

Radespiel, U., Cepok, S., Zietemann, V. \& Zimmermann, E. (1998) Sex-specific usage patterns of sleeping sites in grey mouse lemurs (Microcebus murinus) in Northwestern Madagascar. American Journal of Primatology, 46, 77-84.

Radespiel, U., Sarikaya, Z., Zimmermann, E. \& Bruford, M.W. (2001a) Sociogenetic structure in a free-living nocturnal primate population: sex-specific differences in the grey mouse lemur (Microcebus murinus). Behavioral Ecology and Sociobiology, 50, 493-502.

Radespiel, U., Funk, S.M., Zimmermann, E. \& Bruford, M.W. (2001b) Isolation and characterization of microsatellite loci in the grey mouse lemur (Microcebus murinus) and their amplification in the family Cheirogaleidae. Molecular Ecology Notes, 1, 16-18.

Radespiel, U., Ehresmann, P. \& Zimmermann, E. (2003a) Species-specific usage of sleeping sites in two sympatric mouse lemur species (Microcebus murinus and M. ravelobensis) in northwestern Madagascar. American Journal of Primatology, 59, 139-151.
Radespiel, U., Lutermann, H., Schmelting, B., Bruford, M.W. \& Zimmermann, E. (2003b) Patterns and dynamics of sex-biased dispersal in a nocturnal primate, the grey mouse lemur, Microcebus murinus. Animal Behaviour, 65, 709-719.

Radespiel, U., Rakotondravony, R. \& Chikhi, L. (2008) Natural and anthropogenic determinants of genetic structure in the largest remaining population of the endangered golden-brown mouse lemur, Microcebus ravelobensis. American Journal of Primatology, 70, 860-870.

Radespiel, U., Jurić, M. \& Zimmermann, E. (2009) Sociogenetic structures, dispersal and the risk of inbreeding in a small nocturnal lemur, the golden-brown mouse lemur (Microcebus ravelobensis). Behaviour, 146, 607-628.

Rakotondravony, R. \& Radespiel, U. (2009) Varying patterns of coexistence of two mouse lemur species (Microcebus ravelobensis and M. murinus) in a heterogeneous landscape. American Journal of Primatology, 71, 928-938.

Rambaut, A., Suchard, M.A., Xie, D. \& Drummond, A.J. (2014) Tracer v1.6. Http://tree.bio.ed.ac.uk/software/tracer [accessed 30 April 2018].

Rand, T.A., Tylianakis, J.M. \& Tscharntke, T. (2006) Spillover edge effects: the dispersal of agriculturally subsidized insect natural enemies into adjacent natural habitats. Ecological Letters, 9, 603-614.

Rannala, B. \& Mountain, J.L. (1997) Detecting immigration by using multilocus genotypes. Proceedings of the National Academy of Sciences of the United States of America, 94, 9197-9201.

Rendigs, A., Radespiel, U., Wrogemann, D. \& Zimmermann, E. (2003) Relationship between microhabitat structure and distribution of mouse lemurs (Microcebus spp.) in Northwestern Madagascar. International Journal of Primatology, 24, 47-64.

Ries, L., Fletcher, R.J., Battin, J. \& Sisk, T.D. (2004) Ecological responses to habitat edges: mechanisms, models, and variability explained. Annual Review of Ecology and Systematics, 35, 491-522.

Ries, L., Murphy, S.M., Wimp, G.M. \& Fletcher, R.J. (2017) Closing persistent gaps in knowledge about edge ecology. Current Landscape Ecology Reports, 2, 30-41.

SAGAR, R. \& SINGH, J.S. (2006) Tree density, basal area and species diversity in a disturbed dry tropical forest of northern India: implications for conservation. Environmental Conservation, 33, 256-262.

Sambrook, J., Fritsch, E. \& Maniatis, T. (1989) Molecular Cloning: a Laboratory Manual. Cold Spring Harbor Press, Cold Spring Harbor, USA.

Savolainen, O., Lascoux, M. \& Merila, J. (2013) Ecological genomics of local adaptation. Nature Reviews Genetics, 14, 807-820.

Schliehe-Diecks, S., Eberle, M. \& Kappeler, P.M. (2012) Walk the line-dispersal movements of gray mouse lemurs (Microcebus murinus). Behavioral Ecology and Sociobiology, 66, 1175-1185.

Schwartz, M.K. \& McKelvey, K.S. (2009) Why sampling scheme matters: the effect of sampling scheme on landscape genetic results. Conservation Genetics, 10, 441-452.

Schwitzer, C., Mittermeier, R.A., Johnson, S.E., Donati, G., Irwin, M., Peacock, H. et al. (2014) Averting lemur extinctions amid Madagascar's political crisis. Science, 343, 842-843.

Seutin, G., White, B.N. \& Boag, P.T. (1991) Preservation of avian blood and tissue samples for DNA analysis. Canadian Journal of Zoology, 69, 82-9o.

STAMPS, J.A. (2001) Habitat selection by dispersers: integrating proximate and ultimate approaches. In Dispersal (eds J. Clobert, E. Danchin, A.A. Dhondt \& J.D. Nichols), pp. 230-242. Oxford University Press, New York, USA.

Steffens, T.S. \& Lehman, S.M. (2016) Factors determining Microcebus abundance in a fragmented landscape in Ankarafantsika National Park, Madagascar. In The Dwarf and Mouse Lemurs of Madagascar (eds S.M. Lehman, U. Radespiel \& 
E. Zimmermann), pp. 477-497. Cambridge University Press, Cambridge, UK.

Tamura, K., Peterson, D., Peterson, N., Stecher, G., Nei, M., \& Kumar, S. (2011) MEGA5: Molecular evolutionary genetic analysis using maximum likelihood, evolutionary distance, and maximum parsimony methods. Molecular Biology and Evolution, 28, 2731-2739.

Teuschl, Y., Taborsky, B. \& Taborsky, M. (1998) How do cuckoos find their hosts? The role of habitat imprinting. Animal Behaviour, 56, 1425-1433.

Valenta, K. \& Lehman, S.M. (2016) Microcebus spp. as seed dispersers in the depauperate frugivore communities of Madagascar. In The Dwarf and Mouse Lemurs of Madagascar (eds S.M. Lehman, U. Radespiel \& E. Zimmermann), pp. 353-365. Cambridge University Press, Cambridge, UK.
Weidt, A., Hagenah, N., Randrianambinina, B., Radespiel, U., \& ZimmermanN, E. (2004) Social organization of the golden brown mouse lemur (Microcebus ravelobensis). American Journal of Physical Anthropology 123, 40-51.

Weir, B.S. \& Cockerham, C.C. (1984) Estimating F -statistics for the analysis of population structure. Evolution, 38, 1358-1370.

Williams, G.C. (1966) Adaptation and Natural Selection. Princeton University Press, Princeton, USA.

Williams-Linera, G. \& Lorea, F. (2009) Tree species diversity driven by environmental and anthropogenic factors in tropical dry forest fragments of central Veracruz, Mexico. Biodiversity and Conservation, 18, 3269-3293.

Wilson, G.A. \& Rannala, B. (2003) Bayesian inference of recent migration rates using multilocus genotypes. Genetics, 163, 1177-1191. 